EGU2020-5285

https://doi.org/10.5194/egusphere-egu2020-5285

EGU General Assembly 2020

(c) Author(s) 2020. This work is distributed under

the Creative Commons Attribution 4.0 License.

\title{
Lutetian conid snails from the Paris and Hampshire Basins as seasonality archives of the middle Eocene
}

\author{
Alexander Clark ${ }^{1}$, Johan Vellekoop ${ }^{1,2}$, Zita Keleman ${ }^{1}$, and Robert Speijer ${ }^{1}$ \\ ${ }^{1} \mathrm{KU}$ Leuven, Department of Earth and Environmental Sciences, Belgium \\ ${ }^{2}$ VUB, Analytical, Environmental and Geochemistry Group, Belgium
}

During the Lutetian (middle Eocene, 48-41 Ma), Earth's climate was in transition from greenhouse to icehouse conditions, sometimes referred to as a "doubthouse climate". These circumstances allowed the Paris Basin (France) and Hampshire Basin (UK) to be hotspots for marine biodiversity, hosting a diverse assemblage of molluscs, including members of the Conidae family. Most species within the family are known to live for multiple years, possibly up to a decade, in fully marine conditions and mostly in shallow waters. Under these fully marine conditions, Conidae shells would be excellent recorders of sea water temperatures, allowing paleotemperature reconstruction for the two basins. However, climatic parameters such as temperature extremes or seasonality have not been well documented in the two basins during the Lutetian, with only a handful of studies available [Andreasson \& Schmitz 2000, Huyghe et al. 2015]. Here, we made longitudinal and latitudinal comparisons between the two basins, using carbon and oxygen stable isotope data measured on different Conidae species, in order to provide seasonality reconstructions in north-western Europe. The focus of this research is mainly on assessing isotopic variation of seasonality within a basin and comparison between basins, including previously published data. SEM and cold cathodoluminescence shows that for both basins the preservation of the mollusc carbonate is sufficient to allow for approximations of the original environmental conditions. Three specimens from each basin were sampled by means of manual drilling along the growth axis of the shells. Obtained stable carbon and oxygen isotope data were used to reconstruct variation in paleotemperature and productivity. Following the methodology of Kobashi \& Grossman 2003, patterns in the isotopic signature throughout the life of each specimen give an indication of the environmental reconstruction and any internal variability. By comparing existing and newly collected data from the same localities and family, we examine whether differences in seasonality are species-specific, due to climatic variation, or reflect environmental differences.

Andreasson, F.P., Schmitz, B. (2000) Temperature seasonality in the early middle Eocene North Atlantic region: Evidence from stable isotope profiles of marine gastropod shells, GSA Bulletin, 112, 628-640.

Huyghe, D., Lartaud., F., Emmanuel, L., Merle, D., Renard, M. (2015) Palaeogene climate evolution in the Paris Basin from oxygen stable isotope $(\delta 180)$ compositions of marine molluscs. Journal of the Geological Society, 172, 576-587.

Kobashi, T., Grossman, E.L. (2003) The oxygen isotopic record of seasonality in Conus shells and its application to understanding late middle Eocene (38 Ma) climate, Paleontological Research, 7, 
343-355. 